\title{
Saturação do ozônio em coluna contendo grãos de amendoim e efeito na qualidade
}

\author{
Ozone saturation in a column containing peanut kernels and the effect on quality
}

\section{Matheus de Almeida Roberto ${ }^{1}$, Ernandes Rodrigues de Alencar ${ }^{1 *}$, Wallas Felippe de Souza Ferreira', Marcio Antonio Mendonça ${ }^{1}$, Hanna Alves ${ }^{1}$}

${ }_{1}^{1}$ Universidade de Brasília (UnB), Faculdade de Agronomia e Medicina Veterinária (FAV), Brasília/DF - Brasil

\section{*Corresponding Author}

Ernandes Rodrigues de Alencar, Universidade de Brasília (UnB), Faculdade de Agronomia e Medicina Veterinária (FAV), Campus Darcy Ribeiro, s/n, Asa Norte, CEP: 70910-900,Brasília/DF - Brasil, e-mail: ernandesalencar@unb.br

Cite as: Ozone saturation in a column containing peanut kernels and the effect on quality. Braz. J. Food Technol., v. 19, e2015051, 2016.

Received: July 01, 2015; Accepted: May 31, 2016

\section{Resumo}

Objetivou-se com este trabalho avaliar o processo de saturação do ozônio em coluna contendo amendoim e o efeito na qualidade de produto. Utilizaram-se grãos com teor de umidade em torno de 6,8\% (b.u.), acondicionados em recipientes cilíndricos de PVC, com 1,10 m de altura e $15 \mathrm{~cm}$ de diâmetro. O gás, nas concentrações de 1,59 e 2,78 $\mathrm{mg} \mathrm{L}^{-1}$, foi injetado na base da coluna e os valores adotados de altura da coluna de grãos foram de 0,25, 0,50 e 0,75 m. Determinaram-se os tempos e as concentrações de saturação e avaliou-se a qualidade dos grãos ozonizados. Para os grãos ozonizados na concentração de $1,59 \mathrm{mg} \mathrm{L}^{-1}$, obteve-se tempo de saturação na faixa entre 222 e $449 \mathrm{~min}$. No que tange à relação $\mathrm{C}_{\text {sat }} / \mathrm{C}_{0}$, obtiveram-se valores entre 0,32 e 0,48. Com relação aos grãos submetidos à ozonização na concentração de $2,78 \mathrm{mg} \mathrm{L}^{-1}$, obteve-se tempo de saturação na faixa entre 78 e $251 \mathrm{~min}$. No que se refere à relação $C_{\text {Sal }} / C_{0}$, para a concentração inicial de $2,78 \mathrm{mg} \mathrm{L}^{-1}$, os valores permaneceram entre 0,46 e 0,81. É possível concluir, a partir dos resultados obtidos, que, à medida que se aumenta a altura da coluna de grãos de amendoim, há aumento do tempo de saturação e decréscimo da concentração de saturação. Não houve alteração na qualidade do produto durante o processo de ozonização.

Palavras-chave: Ozonização; Saturação; Alteração qualitativa.

\section{Summary}

The objective of this study was to evaluate the ozone saturation process in a column containing peanuts and the effect on product quality. Peanuts with a moisture content of about 6.8\% (w.b.) were used, packed in cylindrical PVC containers with $1.10 \mathrm{~m}$ in height and $15 \mathrm{~cm}$ in diameter. Ozone was injected into the base of the cylindrical column and the corresponding values adopted for the heights of the grain columns were $0.25,0.50$ and $0.75 \mathrm{~m}$. The peanuts were ozonized at concentrations of 1.59 and $2.78 \mathrm{mg} \mathrm{L}^{-1}$, a temperature of $25^{\circ} \mathrm{C}$ and a gas flow rate of $5.0 \mathrm{~L} \mathrm{~min}^{-1}$. The ozone saturation times and concentrations were determined and also the quality of the ozonized peanuts. For peanut kernels ozonated at a concentration of $1.59 \mathrm{mg} \mathrm{L}^{-1}$, saturation times ranging between 222 and 449 min were obtained. Regarding the $\mathrm{C}_{\mathrm{Sat}} / \mathrm{C}_{0}$ ratio, values between 0.32 and 0.48 were obtained. For peanut kernels ozonated at a concentration of $2.78 \mathrm{mg} \mathrm{L}^{-1}$, saturation times between 78 and 251 min were obtained, and the $\mathrm{C}_{\mathrm{Sat}} / \mathrm{C}_{0}$ ratio for an initial concentration of $2.78 \mathrm{mg} \mathrm{L}^{-1}$ was between 0.46 and 0.81 . It was concluded from the results that an increase in height of the peanut kernel column resulted in an increased saturation time and decreased saturation concentration. There was no change in product quality during the ozonation process.

Keywords: Ozonation; Saturation; Qualitative change.

\section{Introdução}

Os grãos de amendoim se destacam por elevado valor nutricional, sendo importante fonte de óleo e proteína vegetal e de compostos tais como folato, niacina, vitamina e ácidos graxos essenciais (YEH et al., 2002). Entretanto, segundo Sabino et al. (1989), esses grãos são substratos ideais para o desenvolvimento de fungos, que podem produzir as aflatoxinas, metabólitos secundários tóxicos aos homens e animais. A síntese das aflatoxinas ocorre naturalmente e 
é atribuída aos fungos das espécies Aspergillus flavus, Aspergillus parasiticus e também a Aspergillus nomius (PITT, 2000; BLESA et al., 2003). De acordo com Pitt e Hocking (2009), A. flavus é capaz de sintetizar aflatoxina B1 (AFB1) e aflatoxina B2 (AFB2), enquanto que $A$. parasiticus sintetiza AFB1, AFB2, aflatoxina G1 (AFG1) e aflatoxina G2 (AFG2). Salienta-se que AFB1 e AFG1 apresentam maior atividade carcinogênica que AFB2 e AFG2, sendo a AFB1 a de maior toxicidade e um dos mais potentes hepatocarcinógenos naturais (COULOMBE, 1991; OLIVEIRA; GERMANO, 1997).

O gás ozônio tem sido apresentado como uma alternativa para a prevenção e o controle de contaminação de alimentos por aflatoxinas. O ozônio pode evitar e/ou inibir o desenvolvimento dos fungos potencialmente aflatoxigênicos (ALENCAR et al., 2012) e, consequentemente, diminuir o risco de produção de aflatoxinas. Encontram-se, na literatura, diversos relatos que descrevem o efeito do ozônio sobre microrganismos, dentre os quais, os fungos dos gêneros Aspergillus, Fusarium, Geotrichum, Myrothecium, Alternaria, Penicillium, Botrytis e Mucor (RAILA et al., 2006; WU et al., 2006; ZOTTI et al., 2008), além de vírus, protozoários e bactérias (KIM et al., 1999a; KHADRE et al., 2001; AGUAYO et al., 2006; ÖZTEKIN et al., 2006). A inativação de microrganismos pelo ozônio, segundo Cullen et al. (2009), é atribuída, principalmente, à ruptura do envoltório celular e posterior dispersão dos constituintes citoplasmáticos, uma vez que esse gás apresenta alto potencial oxidativo. Essa capacidade do ozônio de inativar ou inibir o desenvolvimento dos microrganismos é fundamental, pois pode representar uma forma de controle de fungos potencialmente aflatoxigênicos e, consequentemente, de prevenção da síntese de aflatoxinas.

Apesar de serem encontrados na literatura muitos relatos referentes ao uso do ozônio como técnica para preservação de alimentos, sendo testado, por exemplo, na degradação de aflatoxinas e inativação de fungos em amendoim (ALENCAR et al., 2012; SAHAB et al., 2013; CHEN et al., 2014), há necessidade de se realizar estudos nos quais seja avaliada a concentração do gás em função da altura da coluna dos grãos. As informações obtidas serão fundamentais na avaliação da viabilidade técnica do processo de ozonização e poderão ser utilizadas no dimensionamento de sistemas industriais de ozonização de grãos de amendoim e outros tipos de grãos com características similares. Tal necessidade se deve à alta reatividade do ozônio em meio contendo matéria orgânica, sendo o gás decomposto em oxigênio. Ressalta-se que o ozônio gasoso, em meio isento de matéria orgânica, apresenta tempo de meia vida menor que $20 \mathrm{~min}$, a $20^{\circ} \mathrm{C}$, segundo Novak e Yuan (2007).

Em vista do exposto, objetivou-se, com este trabalho, determinar o tempo e a concentração de saturação do ozônio, adotando-se diferentes combinações de concentração do gás e altura da coluna de grãos e o efeito na qualidade do produto.

\section{Material e métodos}

O trabalho foi realizado no Laboratório de Pré-Processamento e Armazenamento de Produtos Agrícolas da Faculdade de Agronomia e Medicina Veterinária da Universidade de Brasília.

No processo de ozonização, foram utilizados grãos de amendoim (Arachis hypogaea L.) com umidade de 6,8\% (base úmida). Na geração do ozônio, foi utilizado como insumo oxigênio com grau de pureza de aproximadamente $90 \%$, obtido de concentrador de oxigênio presente no interior do gerador de ozônio. O gás ozônio foi obtido por meio de um gerador de ozônio (Ozone \& Life - Modelo O\&L 3.0 -O2-RM) baseado no método de Descarga por Barreira Dielétrica (DBD). Depois da geração do ozônio, borbulhava-se a mistura de ar contendo o gás em recipiente cilíndrico de vidro com capacidade de 2,0 L, contendo $1,5 \mathrm{~L}$ de solução saturada de $\mathrm{NaCl}$, de tal forma que fosse estabelecida umidade relativa de aproximadamente $75 \%$, seguindo metodologia proposta por Oskan et al. (2011), conforme apresentado na Figura 1. O experimento foi realizado em ambiente climatizado, mantendo-se durante o experimento temperatura em torno de $25^{\circ} \mathrm{C}$.

Ensaios preliminares confirmaram umidade relativa de aproximadamente $75 \%$, após a passagem da massa gasosa contendo ozônio pela solução saturada de $\mathrm{NaCl}$, nas condições apresentadas anteriormente. Na medição da umidade relativa foi utilizado termo-higrômetro digital (Instrutemp - Modelo ITHT2210), com precisão de 4,5\%, na faixa de umidade relativa entre $20 \%$ e $80 \%$ e com resolução de 0,03\%.

Inicialmente os grãos foram acondicionados em coluna cilíndrica de PVC de $15 \mathrm{~cm}$ de diâmetro e $110 \mathrm{~cm}$ de altura. Na base da coluna cilíndrica, foi instalada chapa metálica perfurada com 1,4 mm de espessura, 22,6\% de área perfurada e furos de 5,0 mm de diâmetro para a sustentação dos grãos e a formação de um plenum, para a melhor distribuição do gás. O gás ozônio em mistura com ar, nas concentrações de 1,59 e 2,78 $\mathrm{mg} \mathrm{L}^{-1}$, foi injetado na base da coluna cilíndrica e os valores adotados de altura da coluna de grãos foram de 0,25, 0,50 e 0,75 m, com vazão do gás de $5,0 \mathrm{~L} \mathrm{~min}^{-1}$, na temperatura de $25^{\circ} \mathrm{C}$ (Figura 1).

Determinou-se a concentração residual do ozônio após a passagem do gás pela coluna cilíndrica contendo amendoim, conforme Figura 1, adotando-se diferentes alturas da coluna de grãos. A concentração residual do gás foi determinada até que permanecesse constante. Na concentração inicial do ozônio equivalente a 1,59 $\mathrm{mg} \mathrm{L}^{-1}$, a concentração residual foi quantificada em intervalos regulares de 20 minutos. Com relação à concentração 


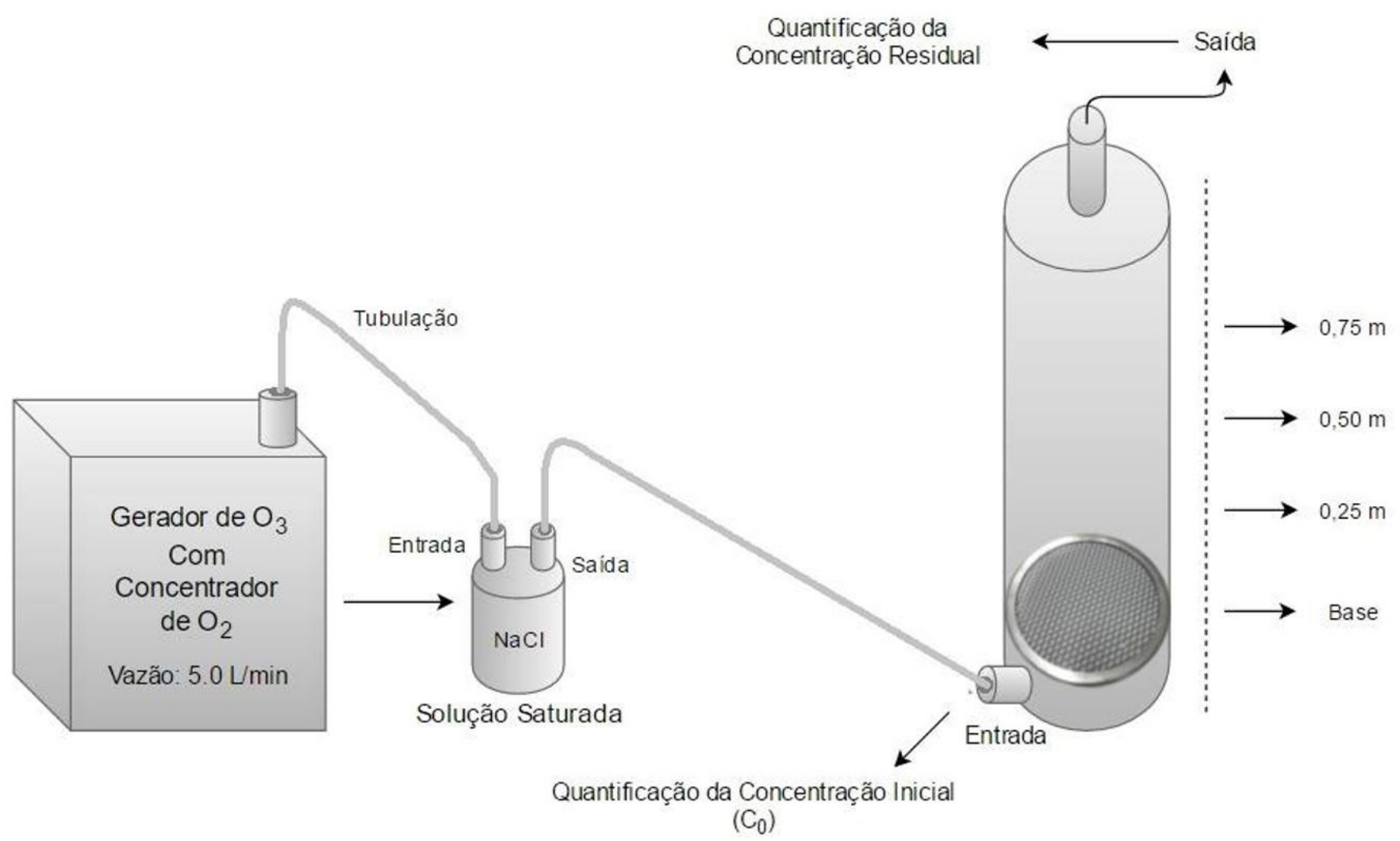

Figura 1. Esquema da ozonização dos grãos de amendoim e quantificação da concentração do gás.

do gás de 2,78 $\mathrm{mg} \mathrm{L}^{-1}$, adotou-se intervalo de 10 minutos até 120 minutos de ozonização. Depois de 120 minutos de ozonização, foi adotado intervalo de 20 minutos. A concentração de ozônio foi determinada pelo método iodométrico, descrito por Clesceri et al. (2000).

Para relacionar concentração residual do gás ozônio com o tempo, realizou-se ajuste da equação sigmoidal aos dados obtidos (Equação 1):

$C=\left[\frac{a}{1+e^{-(t-b) / c}}\right]$

em que

$C=$ concentração do gás ozônio $\left(\mathrm{mg} \mathrm{L}^{-1}\right)$ no ar;

$\mathrm{t}=$ tempo $(\min )$;

$\mathrm{a}, \mathrm{b}$ e c = são as constantes da equação.

A partir dos valores das constantes b e c, de acordo com Venegas et al. (1998), foi possível obter o tempo de saturação para cada combinação de concentração do gás e altura da coluna de grãos (Equação 2):

$t_{\text {Sat }}=b+2 c$

Em que

$\mathrm{t}_{\text {Sat }}=$ tempo de saturação (min).
Conhecendo-se o tempo de saturação $\left(t_{\text {sat }}\right)$, estimou-se a respectiva concentração de saturação $\left(C_{\text {Sat }}\right)$, a partir das equações sigmoidais obtidas para cada uma das combinações de concentração do gás e altura da coluna de grãos. Obteve-se ainda a relação entre a $\mathrm{C}_{\text {Sat }}$ e a concentração inicial do ozônio $\left(C_{0}\right)$.

Na avaliação da qualidade dos grãos ozonizados, depois de homogeneização, analisou-se a umidade dos grãos, teor de ácidos graxos livres e índice de peróxido do óleo bruto extraído do produto ozonizado, com três repetições. A homogeneização foi necessária tendo em vista possível efeito mais intenso do ozônio nos grãos posicionados nas camadas mais próximas à base da coluna. As amostras de cada repetição continham $1 \mathrm{~kg}$ de grãos. Comparou-se a qualidade do amendoim ozonizado nas diferentes condições com grãos não expostos ao gás (testemunha). Destaca-se que o tempo de exposição ao gás foi dependente do processo de saturação. A ozonização, para cada combinação de concentração e altura da coluna de grãos, foi interrompida quando a concentração residual do gás na saída da coluna permaneceu constante.

Para determinação da umidade dos grãos de amendoim, utilizou-se o método de estufa com circulação forçada de ar, à temperatura de $130 \pm 1^{\circ} \mathrm{C}$, por 6 horas, conforme recomendações da ASAE (2002), método S401.1. O óleo bruto foi obtido de acordo com as normas 
Saturação do ozônio em coluna contendo grãos de amendoim e efeito na qualidade

Roberto, M. A. et al.

Firestone (1993), método Ac 3-44, em aparelho de soxhlet, durante 6 horas, utilizando éter de petróleo como solvente. As variáveis teor de ácidos graxos livres e índice de peróxido do óleo bruto foram avaliadas de acordo com as normas Firestone (1993), Métodos Ca 5a-40 e Cd 8-53, respectivamente.

Os experimentos relacionados à obtenção da concentração e do tempo de saturação foram realizados em esquema fatorial $2 \times 3$, sendo duas concentrações (1,59 e 2,78 $\left.\mathrm{mg} \mathrm{L}^{-1}\right)$ e três alturas da coluna de grãos $(0,25$, 0,50 e $0,75 \mathrm{~m}$ ), no delineamento inteiramente casualizado, com três repetições, totalizando 18 ensaios (Tabela 1). No que se refere à qualidade dos grãos, avaliaram-se sete tratamentos, sendo um correspondente aos grãos não ozonizados (testemunha) e seis referentes às diferentes combinações de concentração $\left(1,59\right.$ e 2,78 $\left.\mathrm{mg} \mathrm{L}^{-1}\right)$ e altura da coluna de grãos $(0,25,0,50$ e 0,75 m), com três repetições.

Tabela 1. Matriz de planejamento dos experimentos relacionados ao processo de ozonização dos grãos de amendoim.

\begin{tabular}{ccc}
$\begin{array}{c}\text { Concentração do } \\
\text { gás } \\
\left(\mathbf{m g ~ L}^{-1}\right)\end{array}$ & $\begin{array}{c}\text { Altura da coluna } \\
\text { de grãos }(\mathbf{m})\end{array}$ & $\begin{array}{c}\text { Número de } \\
\text { repetições }\end{array}$ \\
\multirow{2}{*}{1,59} & 0,25 & 3 \\
& 0,50 & 3 \\
& 0,75 & 3 \\
2,78 & 0,25 & 3 \\
& 0,50 & 3 \\
\hline
\end{tabular}

Para a obtenção das equações na análise de regressão e plotagem dos gráficos, referentes ao tempo e concentração de saturação, utilizou-se o software SigmaPlot v.10.0. Quanto aos dados referentes à qualidade dos grãos ozonizados, realizou-se análise de variância a 5\% de probabilidade e, sendo obtida variação significativa, Teste de Tukey, utilizando-se o software Statplus v.5.

\section{Resultados e discussão}

Na Figura 2, são apresentadas as curvas referentes à concentração de ozônio em função do período de exposição, durante o processo de saturação do meio poroso contendo grãos de amendoim, quando adotadas as concentrações de 1,59 e 2,78 $\mathrm{mg} \mathrm{L}^{-1}$, alturas da coluna de grãos equivalente a $0,25,0,50$ e $0,75 \mathrm{~m}$, vazão de $5,0 \mathrm{~L} \mathrm{~min}{ }^{-1}$ e temperatura de $25^{\circ} \mathrm{C}$. Apresentam-se, na Tabela 2, as equações de regressão ajustadas e os seus respectivos coeficientes de determinação, que relacionam o ozônio residual e o período de exposição ao gás.

Os resultados observados referentes à concentração residual do ozônio nos grãos de amendoim durante o processo de saturação, nas diferentes combinações de concentração inicial e altura da coluna dos grãos, seguiram tendência semelhante à descrita por Strait (1998), Kells et al. (2001) e Mendez et al. (2003). De acordo com esses autores, o movimento do ozônio em meio poroso contendo grãos apresenta duas fases. Na primeira fase, o gás reage com sítios ativos na superfície do produto no início da ozonização, ocorrendo degradação do ozônio e, consequentemente, eliminação desses sítios ativos. Uma vez que os sítios ativos são eliminados, o ozônio se move através do meio poroso, com taxa de degradação
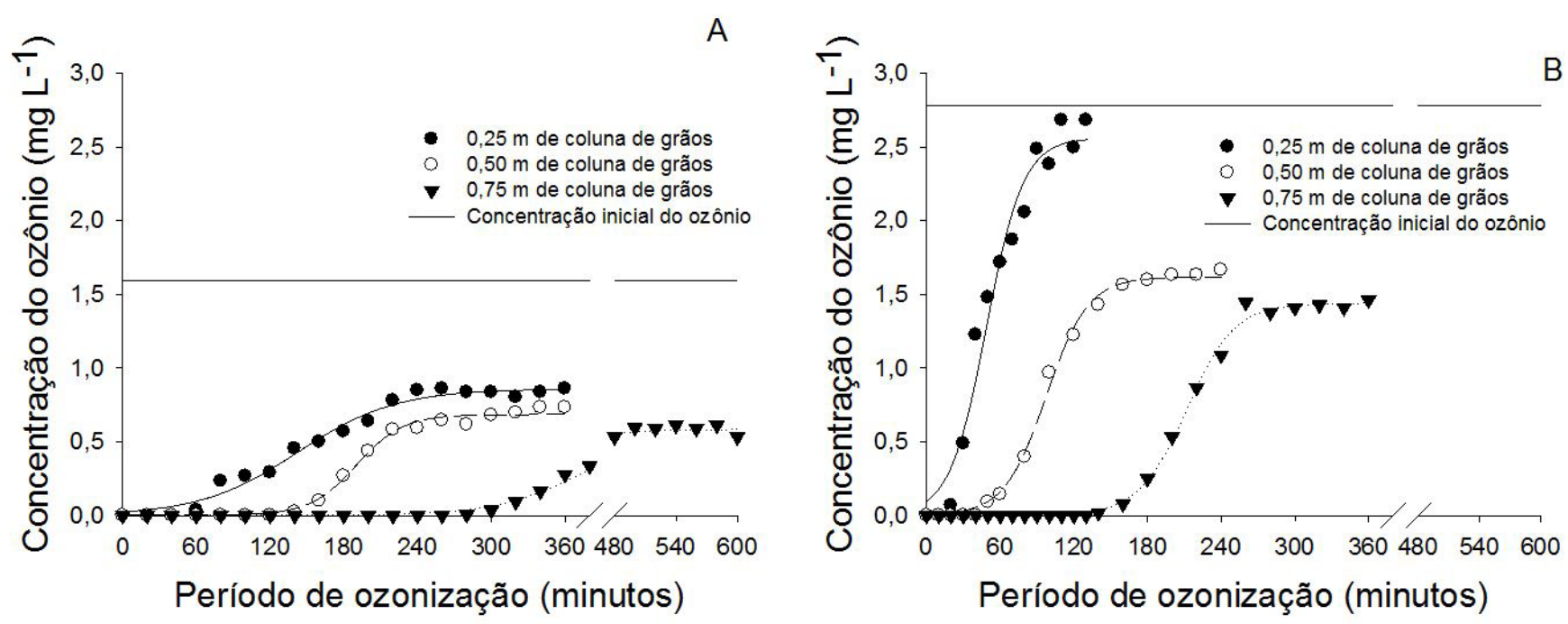

Figura 2. Concentração residual do ozônio $\left(\mathrm{mg} \mathrm{L}^{-1}\right)$ na saída de coluna contendo grãos de amendoim com 6,8\% (b.u.) de umidade, em função do tempo para concentrações iniciais do gás de 1,59 (A) e 2,78 (B) $\mathrm{mg} \mathrm{L}^{-1}$, alturas da coluna de grãos equivalentes a $0,25,0,50$ e $0,75 \mathrm{~m}$, vazão de $5,0 \mathrm{~L} \mathrm{~min}^{-1}$ e na temperatura de $25^{\circ} \mathrm{C}$. 
Saturação do ozônio em coluna contendo grãos de amendoim e efeito na qualidade

Roberto, M. A. et al.

Tabela 2. Equações de regressão ajustadas e respectivos coeficientes de determinação $\left(R^{2}\right)$ para concentração residual do ozônio ( $m g \mathrm{~L}^{-1}$ ) durante o processo de saturação de amendoim com 6,8\% (b.u.) de umidade, alturas da coluna de grão equivalente a $0,25,0,50$ e $0,75 \mathrm{~m}$, vazão de $5,0 \mathrm{~L} \mathrm{~min}{ }^{-1}$, na temperatura de $25^{\circ} \mathrm{C}$, e concentrações iniciais de 1,59 e $2,78 \mathrm{mg} \mathrm{L}^{-1}$.

\begin{tabular}{|c|c|c|c|c|c|c|}
\hline $\begin{array}{l}\text { Concentração } \\
\text { Inicial - } \mathrm{C}_{0} \\
\left(\mathrm{mg} \mathrm{L}^{-1}\right)\end{array}$ & $\begin{array}{c}\text { Altura da coluna } \\
\text { de grãos (m) }\end{array}$ & Equações ajustadas & $\mathbf{R}^{2}$ & $t_{\text {sat }}(\mathrm{min})$ & $\begin{array}{c}\mathrm{C}_{\text {Sat }} \\
\left(\mathrm{mg} \mathrm{L}^{-1}\right)\end{array}$ & $\mathrm{C}_{\mathrm{Sat}} / \mathrm{C}_{0}$ \\
\hline \multirow{3}{*}{1,59} & 0,25 & $\hat{C}=\frac{0,86}{1+e^{-\left(\frac{t-142,64}{39,84}\right)}}$ & 0,98 & 222,30 & 0,76 & 0,48 \\
\hline & 0,50 & $\hat{C}=\frac{0,68}{1+e^{-\left(\frac{t-190,41}{19,09}\right)}}$ & 0,99 & 228,60 & 0,60 & 0,38 \\
\hline & 0,75 & $\hat{C}=\frac{0,58}{1+e^{-\left(\frac{t-375,97}{36,38}\right)}}$ & 0,99 & 448,73 & 0,51 & 0,32 \\
\hline \multirow{3}{*}{2,78} & 0,25 & $\hat{C}=\frac{2,56}{1+e^{-\left(\frac{t-48,84}{15,01}\right)}}$ & 0,97 & 78,86 & 2,25 & 0,81 \\
\hline & 0,50 & $\hat{C}=\frac{1,62}{1+e^{-\left(\frac{t-97,41}{17,09}\right)}}$ & 0,99 & 131,60 & 1,43 & 0,51 \\
\hline & 0,75 & $\hat{C}=\frac{1,44}{1+e^{-\left(\frac{t-211,77}{19,54}\right)}}$ & 0,99 & 250,85 & 1,27 & 0,46 \\
\hline
\end{tabular}

$\mathrm{t}_{\mathrm{Sat}}=$ Tempo de saturação. $\mathrm{C}_{\mathrm{Sat}}=$ Concentração de saturação.

reduzida, estabelecendo-se a segunda fase do processo. Comportamento similar foi observado por Alencar et al. (2011a), que ozonizaram grãos de amendoim com valores de umidade equivalente a $7,1 \%$ e $10,5 \%$ (b.u.), nas temperaturas de 25 e $35^{\circ} \mathrm{C}$.

Com relação aos grãos ozonizados na concentração de 1,59 mg $\mathrm{L}^{-1}$, obteve-se tempo de saturação na faixa entre 222 e 449 min, sendo o maior valor obtido quando se adotou coluna com 0,75 m (Tabela 2). No que tange à relação $\mathrm{C}_{\mathrm{Sat}} / \mathrm{C}_{0}$, obtiveram-se valores entre 0,32 e 0,48. No que se refere aos grãos de amendoim submetidos à ozonização na concentração de $2,78 \mathrm{mg} \mathrm{L}^{-1}$, obteve-se tempo de saturação na faixa entre 78 e 251 mim. Nessa condição, os valores referentes à relação $\mathrm{C}_{\mathrm{Sat}} / \mathrm{C}_{0}$ permaneceram entre 0,46 e 0,81 , sendo o maior valor obtido quando se adotou a altura da coluna de grãos de 0,25 m. Dessa forma, à medida que se eleva a concentração inicial do gás, atinge-se a concentração de saturação do meio poroso em menor tempo. Todavia, à medida que se adota maior concentração inicial do gás, é verificada maior diferença na relação $\mathrm{C}_{\text {sat }} / \mathrm{C}_{0}$ entre as camadas inferiores e superiores da coluna de grãos.

Salienta-se que, em todas as combinações testadas (concentração do ozônio versus altura da coluna de grãos), foi obtida concentração de saturação do gás na saída do sistema inferior à concentração inicial $\left(C_{0}\right)$. O ozônio se destaca por sua alta reatividade e pela decomposição em um produto não tóxico, que é o oxigênio (KIM et al., 1999b; CULLEN et al., 2009). Nesse sentido, tem-se que a degradação do ozônio ocorre, ao longo da coluna, mesmo que em taxa reduzida (STRAIT, 1998), influenciando, dessa forma, a concentração residual na saída do sistema. Outros fatores podem influenciar o processo de saturação, tais como umidade do produto, temperatura e vazão do gás (ALENCAR et al., 2011a).

Dessa forma, tem-se que os menores tempos de saturação e maiores valores referentes à relação $\mathrm{C}_{\mathrm{Sat}} / \mathrm{C}_{0}$ foram obtidos quando se adotou $0,25 \mathrm{~m}$ de coluna de grãos, independentemente da concentração inicial do ozônio. Entretanto, para as alturas de coluna de grãos equivalentes a 0,50 e 0,75 m, foram obtidos valores de concentração residual superiores a valores encontrados na literatura e que podem ser eficazes no controle de insetos-praga e de microrganismos. Concentração de $0,11 \mathrm{mg} \mathrm{L}^{-1}$ de gás ozônio foi suficiente para controlar Tribolium castaneum Herbst (Coleoptera: Tenebrionidae), importante espécie de inseto-praga de grãos armazenados (PEREIRA et al., 2008). Kells et al. (2001) adotaram concentração de $0,11 \mathrm{mg} \mathrm{L}^{-1}$ na ozonização de grãos de milho, por período de três dias, e conseguiram reduzir em 63\% a infecção superficial pela espécie potencialmente aflatoxigênica Aspergillus parasiticus. 
No que se refere à qualidade dos grãos ozonizados, não foi detectada variação significativa para as variáveis umidade dos grãos e percentual de ácidos graxos livres e índice de peróxido do óleo bruto ( $p>0,05)$, em decorrência das diferentes combinações de concentração do gás e altura da coluna dos grãos, de acordo com a Análise de Variância (Tabela 3). Os valores médios referentes à umidade dos grãos, ao percentual de ácidos graxos livres e ao índice de peróxido do óleo bruto são apresentados na Tabela 4.

A umidade dos grãos permaneceu na faixa entre $6,68 \%$ e 6,90\% (Tabela 4). Verificou-se, nas condições adotadas no trabalho, que a ozonização não influencia a umidade dos grãos. Os resultados obtidos referentes à umidade dos grãos podem ser explicados pelo fato de que, depois da geração do ozônio e antes de se injetar o gás na coluna dos grãos, a mistura gasosa passava por solução saturada de $\mathrm{NaCl}$, para a manutenção da umidade relativa em torno de $75,0 \%$. É importante salientar que a umidade relativa durante a ozonização é determinante para a manutenção da umidade do produto e também na inativação de microrganismos. De acordo com Oskan et al. (2011), é possível obter maior eficiência à medida que se eleva a umidade relativa da mistura gasosa que contém ozônio.

O percentual de ácidos graxos livres do óleo bruto permaneceu na faixa entre $1,10 \%$ e $1,45 \%$, nas diferentes combinações de concentração do ozônio e altura da coluna de grãos $(p>0,05)$. Outro aspecto relevante é que os valores médios obtidos de ácidos graxos livres do óleo bruto extraído dos grãos ozonizados permaneceram abaixo do limite exigido pela Anvisa (BRASIL, 1999) para comercialização de óleo bruto de amendoim, que é de $2,00 \%$. Esses resultados confirmam os resultados obtidos por Akbas e Ozdemir (2008), que não observaram aumento do percentual de ácidos graxos livres no óleo bruto extraído de pistaches ozonizados nas concentrações de 5,0, 7,0 e 9,0 $\mathrm{mg} \mathrm{L}^{-1}$, por períodos de exposição de até 420 min. Alencar et al. (2011b) também não observaram variação no percentual de ácidos graxos livres em óleo bruto extraído de grãos de amendoim ozonizados nas concentrações de 13 e $21 \mathrm{mg} \mathrm{L}^{-1}$, por até 96 horas.

Com relação ao índice de peróxido do óleo bruto extraído dos grãos de amendoim (Tabela 4), não foi verificada variação significativa em decorrência das diferentes combinações de concentração do ozônio e altura da coluna de grãos $(p>0,05)$. Os valores médios de índice de peróxido do óleo bruto de amendoim permaneceram na faixa entre 10,17 e 14,57 meq $\mathrm{kg}^{-1}$. Entretanto, Sanchez et al. (2016) avaliaram a qualidade de amendoim ozonizado na concentração de 2,77 mg L-1, por 12 horas, em diferentes pontos de coluna de 0,75 m de grãos. Os autores observaram maiores valores de índice de peróxido nas camadas mais próximas à base da coluna de grãos. Tem-se ainda que os valores médios do índice de peróxido, independentemente do tratamento, permaneceram acima de 10 meq $\mathrm{kg}^{-1}$ de amostra, limite estabelecido no Brasil para comercialização de óleo bruto de amendoim (BRASIL, 1999).

Tabela 3. Análise de variância e coeficiente de variação da umidade dos grãos (\%), do teor de ácidos graxos livres (\%) e do índice de peróxido (meq $\mathrm{kg}^{-1}$ ) do óleo bruto extraído de amendoim submetido a diferentes combinações de concentração do ozônio $\left(m g L^{-1}\right)$ e de altura da coluna de grãos $(m)$.

\begin{tabular}{ccccc} 
Fonte de Variação & G.L. & Umidade & Teor de ácidos graxos livres & Índice de peróxido \\
\hline Tratamentos & 6 & $0,01629^{\text {ns }}$ & $0,04103^{\text {ns }}$ & $8,57816^{\mathrm{ns}}$ \\
Resíduo & 14 & 0,02393 & 0,03397 & 12,60475 \\
CV $(\%)$ & & 2,29 & 14,57 & 19,78 \\
\hline
\end{tabular}

ns Não significativo a $5 \%$ de probabilidade pelo teste $\mathrm{F}$.

Tabela 4. Valores médios da umidade dos grãos (\%), do teor de ácidos graxos livres (\%) e do índice de peróxido (meq $\left.\mathrm{kg}^{-1}\right)$ do óleo bruto extraído de amendoim submetido a diferentes combinações de concentração do ozônio (mg L $\mathrm{L}^{-1}$ ) e de altura da coluna de grãos (m).

\begin{tabular}{|c|c|c|c|}
\hline Tratamento & Umidade (\%) & $\begin{array}{c}\text { Teor de ácidos graxos } \\
\text { livres (\%) }\end{array}$ & $\begin{array}{l}\text { Índice de peróxido } \\
\left.\text { (meq } \mathbf{k g}^{-1}\right)\end{array}$ \\
\hline Testemunha & $6,90 \pm 0,18$ & $1,41 \pm 0,21$ & $10,60 \pm 1,51$ \\
\hline $1,59 \mathrm{mg} \mathrm{L}^{-1} \times 0,25 \mathrm{~m}$ & $6,75 \pm 0,05$ & $1,45 \pm 0,26$ & $13,62 \pm 1,94$ \\
\hline $1,59 \mathrm{mg} \mathrm{L}^{-1} \times 0,50 \mathrm{~m}$ & $6,78 \pm 0,14$ & $1,14 \pm 0,14$ & $10,17 \pm 1,09$ \\
\hline $1,59 \mathrm{mg} \mathrm{L}^{-1} \times 0,75 \mathrm{~m}$ & $6,68 \pm 0,18$ & $1,21 \pm 0,17$ & $11,71 \pm 0,34$ \\
\hline $2,78 \mathrm{mg} \mathrm{L}^{-1} \times 0,25 \mathrm{~m}$ & $6,73 \pm 0,19$ & $1,25 \pm 0,15$ & $14,57 \pm 1,08$ \\
\hline $2,78 \mathrm{mg} \mathrm{L}^{-1} \times 0,50 \mathrm{~m}$ & $6,83 \pm 0,09$ & $1,22 \pm 0,18$ & $12,37 \pm 0,75$ \\
\hline $2,78 \mathrm{mg} \mathrm{L}^{-1} \times 0,75 \mathrm{~m}$ & $6,72 \pm 0,19$ & $1,19 \pm 0,14$ & $10,43 \pm 0,58$ \\
\hline
\end{tabular}


Saturação do ozônio em coluna contendo grãos de amendoim e efeito na qualidade

Roberto, M. A. et al.

\section{Conclusão}

A análise e interpretação dos dados permitiram concluir que, à medida que se aumenta a altura da coluna de grãos de amendoim, há aumento do tempo de saturação e decréscimo da concentração de saturação. Quando se eleva a concentração inicial do gás, obtêm-se menores tempos de saturação e maiores valores da relação $\mathrm{C}_{\mathrm{Sat}} / \mathrm{C}_{0}$. Nas condições adotadas no trabalho, a ozonização não provoca alteração na umidade do amendoim e no teor de ácidos graxos livres e no índice de peróxido do óleo bruto extraído dos grãos ozonizados.

\section{Agradecimentos}

Ao Conselho Nacional de Desenvolvimento Científico e Tecnológico (CNPq) pelo auxílio financeiro e concessão de bolsa.

\section{Referências}

AGUAYO, E.; ESCALONA, V. H.; ARTES, F. Effect of cyclic exposure to ozone gas on physicochemical, sensorial and microbial quality of whole and sliced tomatoes. Postharvest Biology and Technology, Amsterdan, v. 39, p. 169-177, 2006.

AKBAS, M. Y.; OZDEMIR, M. Application of gaseous ozone to control populations of Escherichia coli, Bacillus cereus and Bacillus cereus spores in dried figs. Food Microbiology, London, v. 25, p. 386-391, 2008.

ALENCAR, E. R.; FARONI, L. R. D.; MARTINS, M. A.; COSTA, A. R.; CECON, P. R. Decomposition kinetics of gaseous ozone in peanuts. Engenharia Agrícola, Jaboticabal, v. 31, p. 930-939, 2011a.

ALENCAR, E. R.; FARONI, L. R. D.; SOARES, N. F. F.; CARVALHO, M. C. S.; PEREIRA, K. F. Effect of the ozonization process on the quality of peanuts and crude oil. Revista Brasileira de Engenharia Agrícola e Ambiental, Campina Grande, v. 15, p. 154-160, 2011b.

ALENCAR, E. R.; FARONI, L. R. D.; SOARES, N. F. F.; SILVA, W. A.; CARVALHO, M. C. S. Efficacy of ozone as a fungicidal and detoxifying agent of aflatoxins in peanuts. Journal of the Science of Food and Agriculture, London, v. 92, n. 4, p. 899-905, 2012. http://dx.doi.org/10.1002/jsfa.4668. PMid:22095762.

AMERICAN SOCIETY OF AGRICULTURAL ENGINEERS - ASAE. ASAE S410.1: Moisture measurement: peanuts. In: ASAE Standards. St. Joseph: ASAE, 2002. p. 600-601.

BLESA, J.; SORIANO, J. M.; MOLTO, J. C.; MARIN, R.; MANES, $J$. Determination of aflatoxins in peanuts by matrix solid-phase $q$ dispersion and liquid chromatography. Journal of Chromatography A, Amsterdam, v. 1011, n. 1-2, p. 49-54, 2003. http://dx.doi. org/10.1016/S0021-9673(03)01102-6. PMid:14518762.

BRASIL. Agência Nacional de Vigilância Sanitária. Resolução $n^{\circ}$ 482, de 23 de setembro de 1999. Regulamento técnico para fixação de identidade e qualidade de óleos e gorduras vegetais. Diário Oficial [da] República Federativa do Brasil, Brasília, DF, 23 set. 1999. 5 p.

CHEN, R.; MA, F.; LI, P. W.; ZHANG, W.; DING, X. X.; ZHANG, Q.; LI, M.; WANG, Y. R.; XU, B. C. Effect of ozone on aflatoxins detoxification and nutritional quality. Food Chemistry, London, v. 146, p. $284-288,2014$

CLESCERI, L. S.; GREENBERG, A. E.; EATON, A. D. Standard methods for the examination of water and wastewater. Denver: American Water Works Association, 2000. 1220 p.

COULOMBE, R. A. Aflatoxins. In: SHARMA, R. P.; SALUNKHE, D. K. (Ed.). Mycotoxins and phytoalexins. Boca Raton: CRC Press, 1991. p. 103-144

CULLEN, P. J.; TIWARI, B. K.; O'DONNELL, C. P.; MUTHUKUMARAPPAN, K. Modelling approaches to ozone processing of liquid foods. Trends in Food Science \& Technology, Oxford, v. 20, p. 125-136, 2009.

FIRESTONE, D. (Ed.). Official methods and recommended practices of the AOCS. 4th. ed. Champaign: AOCS, 1993. v. $1-2,1200 \mathrm{p}$.

KELLS, S. A.; MASON, L. J.; MAIER, D. E.; WOLOSHUK, C. P. Efficacy and fumigation characteristics of ozone in stored maize. Journal of Stored Products Research, Oxford, v. 37, n. 4, p. 371-383, 2001. http://dx. doi.org/10.1016/S0022-474X(00)00040-0. PMid:11463399

KHADRE, M. A.; YOUSEF, A. E.; KIM, J. G. Microbiological aspects of ozone applications in food: a review. Journal of Food Science, Chicago, v. 66, n. 9, p. 1242-1252, 2001. http:// dx.doi.org/10.1111/j.1365-2621.2001.tb15196.x.

KIM, J. G.; YOUSEF, A. E.; CHISM, G. W. Use of ozone to inactivate microorganisms on lettuce. Journal of Food Safety, Westport, v. 19, n. 1, p. 17-34, 1999a. http://dx.doi.org/10.1111/j.1745-4565.1999. tb00231.x.

KIM, J. G.; YOUSEF, A. E.; DAVE, S. Application of ozone for enhancing the microbiological safety and quality of foods: a review. Journal of Food Protection, Des Moines, v. 62, n. 9, p. 1077-1087, 1999b. PMid:10492485.

MENDEZ, F.; MAIER, D. E.; MASON, L. J.; WOLOSHUK, C. P. Penetration of ozone into columns of stored grains and effects on chemical composition and performance. Journal of Stored Products Research, Oxford, v. 39, n. 1, p. 33-44, 2003. http:// dx.doi.org/10.1016/S0022-474X(02)00015-2.

NOVAK, J. S.; YUAN, J. T. C. The ozonation concept: advantages of ozone treatment and commercial developments. In: TEWARI, G.; JUNEJA, V. K. (Ed.). Advances in thermal and non-thermal food preservation. Ames: Blackwell Publishing, 2007, p. 185-193.

OLIVEIRA, C. A. F.; GERMANO, P. M. L. Aflatoxinas: conceitos sobre mecanismos de toxicidade e seu envolvimento na etiologia 
Saturação do ozônio em coluna contendo grãos de amendoim e efeito na qualidade

Roberto, M. A. et al.

do câncer hepático celular. Revista de Saúde Pública, São Paulo, v. 31, p. 417-424, 1997.

OSKAN, R.; SMILANICK, J. L.; KARABULUT, O. A. Toxicity of ozone gas to conidia of Penicillium digitatum, Penicillium italicum, and Botrytis cinerea and control of gray mold on table grapes. Postharvest Biology and Technology, Amsterdan, v. 60, p. 47-51, 2011.

ÖZTEKIN, S.; ZORLUGENC, B.; ZORLUGENC, F. K. Effects of ozone treatment on microflora of dried figs. Journal of Food Engineering, Kidlington, v. 75, n. 3, p. 396-399, 2006. http:// dx.doi.org/10.1016/j.jfoodeng.2005.04.024.

PEREIRA, A. M.; FARONI, L. R. D.; SOUSA, A. H.; URRUCHI, W. I.; PAES, J. L. Influência da temperatura da massa de grãos sobre a toxicidade do ozônio a Tribolium castaneum. Revista Brasileira de Engenharia Agrícola e Ambiental, Campina Grande, v. 12, p. 493-497, 2008.

PITT, J. I. Toxigenic fungi: which are important? Medical Mycology, Oxford, v. 38, p. 17-22, 2000. Suplemento 1. http:// dx.doi.org/10.1080/mmy.38.1.17.22. PMid:11204142.

PITT, J. I.; HOCKING, A. D. Fungi and food spoilage. 2nd. ed. New York: Springer, 2009. 519 p.

RAILA, A.; LUGAUSKAS, A.; STEPONAVI IUS, D.; RAILIEN, M.; STEPONAVI IEN , A.; ZVICEVI IUS, E. Application of ozone for reduction of mycological infection in wheat grain. Annals of Agricultural and Environmental Medicine, Lublin, v. 13, p. 287-294, 2006.

SABINO, M.; ZORBETT, M. A. P.; PEDROSO, M. O.; MILANEZ, T. $\checkmark$. Incidência de aflatoxinas em amendoim e produtos derivados consumidos na cidade de São Paulo, no período de 1980 a 1987. Revista do Instituto Adolfo Lutz, São Paulo, v. 49, p. 41-44, 1989.
SAHAB, F. A. F.; HASSANIEN, F. R.; EL-NEMR, S. E.; ABDELALIM, H. A.; ABDEL-WAHHAB, M. A. Effect of ozone gaseous on aflatoxin degradation and fat and protein content in peanut seeds. Journal of Applied Sciences Research, Faisalabad, v. 9, p. 2170-2175, 2013

SANCHEZ, B. A. O.; ALENCAR, E. R.; PINELI, L. L. O.; FERREIRA, W. F. S.; ROBERTO, M. A. Tracing interactions among column height, exposure time and gas concentration to dimension peanut antifungal ozonation. LWT - Food Science and Technology, Zurich, v. 65, p. 668-675, 2016.

STRAIT, C. A. Efficacy of ozone to control insects and fungi in stored grain. 1998. 59 p. Dissertation (Master of Science)Department of Entomology, Purdue University, West Lafayette, 1998.

VENEGAS, J. G.; HARRIS, R. S.; SIMON, B. A. A comprehensive equation for the pulmonary pressure-volume curve. American Physiological Society, Washington, v. 84, p. 389-395, 1998.

WU, J.; DOAN, H.; CUENCA, M. A. Investigation of gaseous ozone as an anti-fungal fumigant for stored wheat. Journal of Chemical Technology \& Biotechnology, Oxford, v. 81, n. 7, p. 1288-1293, 2006. http://dx.doi.org/10.1002/jctb. 1550.

YEH, J.; PHILLIPS, R. D.; RESURRECCION, A. V. A.; HUNG, Y. Physicochemical and sensory characteristic changes in fortified peanut spreads after 3 months of storage at different temperatures. Journal of Agricultural and Food Chemistry, Washington, v. 50, n. 8, p. 2377-2384, 2002. http://dx.doi.org/10.1021/jf011258r. PMid:11929300.

ZOTTI, M.; PORRO, R.; VIZZINI, A.; MARIOTTI, M. G. Inactivation of Aspergillus spp. by ozone treatment. Ozone-Science \& Engineering, Hants, v. 30, p. 423-430, 2008. 